ISSN electrónico: 2172-9077

https://doi.org/10.14201/fjc201715145162

\title{
El Festival de EuRovisión: MÁs ALLÁ DE LA CANCiÓN
}

\section{Eurovision Song Contes, beyond the Song}

\author{
Laura ORTIZ MONTERO \\ España \\ E-Mail: laura-badajoz@hotmail.com \\ (iD) orcid.org/0000-0001-6185-2846
}

\begin{abstract}
RESUMEN
La Unión Europea de Radiodifusión (UER) nació en 1950 para mejorar el servicio de radio y televisión mediante la colaboración y el intercambio de contenidos. Este, en un principio, se limitaba solo a noticias y deportes. Para aumentar sus servicios, en 1956 apostaron por crear un certamen donde la música sirviera de nexo de unión entre los pueblos: el Festival de Eurovisión. Sesenta y un años más tarde, el Festival se ha convertido en uno de los programas de televisión más longevo del mundo, así como uno de los eventos que cuenta con más audiencia. Esta investigación pretende conocer si el Festival cumple con los objetivos de la UER, señalados en sus estatutos, que hacen referencia a la diversidad cultural e identidad de los pueblos.
\end{abstract}

Palabras clave: Festival de Eurovisión; diversidad cultural; identidad de los pueblos; Unión Europea de Radiodifusión.

\begin{abstract}
The European Broadcasting Union (EBU) was born in 1950 to improve service radio and television through collaboration and sharing content. This was, initially, limited only to news and sports. Therefore, in order not to be based only on that content, in 1956 they opted to create an event where music was a link between peoples: the Eurovision Song Contest. Sixty-one years later, the Song Contest has become one of the longest running programs in television in the world as well as one of the events that have the highest audience. The objective of this research is to know if the Eurovision Song Contest fulfills the purposes of the EBU, which refer to cultural diversity and the identity of peoples.
\end{abstract}

Key words: Eurovision Song Contest; cultural diversity; identity of people; European Broadcasting Union.

Fecha de recepción del artículo: 29/09/2016

Fecha de aceptación definitiva: 14/06/2017

\section{INTRODUCCIÓN}

La Unión Europea de Radiodifusión (UER) nació en 1950 para mejorar el servicio de radio y televisión mediante la colaboración, la asistencia técnica, el intercambio de contenidos y la defensa conjunta de sus intereses. Ese intercambio en un principio se limitaba solo a noticias y deportes. Por ello, para aumentar sus servicios, en 1956 la UER apostó por crear un certamen en donde la música sirviera de nexo de unión entre los pueblos: el Festival de la Canción de Eurovisión.

Año tras año, festival tras festival, las opiniones se han ido diversificando. Parece que no hay duda de que en sus inicios fue un espectáculo televisivo que hacía que las familias de Europa se reunieran 
alrededor del televisor para contemplarlo. Así, los 50 fueron el inicio del «fenómeno Eurovisión»; los 60 la consagración del Festival; los 70, Eurovisión superastro; los 80, Eurovisión hace aguas; los 90, el renacimiento; el siglo XXI, Eurovisión es todo un fenómeno (Ayllón, et al., 2004).

No hay una definición exacta de lo que es el Festival de Eurovisión y, tras 61 ediciones, definirlo es una tarea complicada. Sin embargo, Cebrián Herreros en su libro Estrategia multimedia de la televisión en Operación Triunfo afirma:

Es un festival que cuenta con larga trayectoria, va por la 47 edición, y que ha tenido altibajos en la audiencia, pero sigue gozando de amplio atractivo. En la edición (2001) se superaron los 100 millones de telespectadores de 30 países y unos seis millones de seguidores por Internet. En España en 2001 se alcanzó una audiencia de 5.613 .000 telespectadores, un $457 \%$ de cuota. En la convocatoria de 2003 , participaron 24 países. (Cebrián Herreros, 2003, p. 5).

En la actualidad, es uno de los programas de televisión más longevos del mundo y uno de los eventos que cuenta con más audiencia. En 2016 ha conseguido reunir a 204 millones de telespectadores.

Gráfico 1. Evolución de la audiencia del Festival de Eurovisión en España - ESPECTADORES

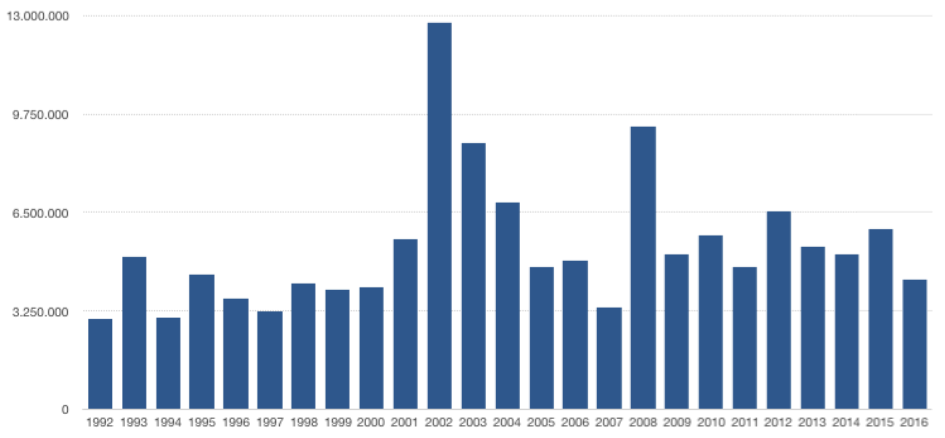

Fuente: elaboración propia a partir de datos recogidos en Eurovision-Spain.

La UER explica que el Festival aporta a los servicios públicos valores como el respeto, la creatividad, la diversidad y la innovación, además de los valores europeos. En definitiva, Eurovisión es más que música; es un formato televisivo que con los años se reinventa y que ha sabido adaptarse a los tiempos. Eurovisión es más que cuarenta países; es más que un programa visual. Es un programa social, político, cultural, económico, y tecnológico, que impacta en Europa y fuera de ella.

Pertenezco a la generación que descubrió y se enganchó a Eurovisión gracias al nacimiento de un programa que revolucionó la televisión: Operación Triunfo. Por aquel entonces, 2002, dieciséis jóvenes competían en un concurso musical cuyo premio era, además de hacerse un hueco en la industria musical, tener la oportunidad de representar a España en el Festival. Tal y como indica Pardo (2005, p. 82), ese año hubo audiencias superiores a los diez millones de espectadores y achaca a que la peripecia personal de Rosa (ganadora de la primera edición de Operación Triunfo), su carisma y simpatía «hicieron que de nuevo toda España se encontrara frente al televisor haciendo quinielas sobre una edición del Festival, algo que no sucedía desde los años 70».

La justificación de la elección del tema y su posterior acotamiento viene motivada por el hecho de que, tras haber realizado una búsqueda exhaustiva de la literatura existente sobre el mismo, nos hemos dado cuenta de que esta es escasa. Y de la misma forma podemos concluir que la bibliografía escrita en castellano sobre el Festival es prácticamente inexistente. 
Estudiar el fenómeno de Eurovisión permite al investigador aproximarse al objeto de estudio desde diferentes disciplinas. El primer estudio académico que se cita en todas las investigaciones sobre el Festival es uno que procede del campo de las matemáticas y de la estadística. Yair Gad (1995) en «Unite Unite Europe: The Political and Cultural Structure of Europe as Reflected in the Eurovision Song Contest», a partir de un estudio estadístico desarrolla la teoría de los bloques. En ella, se afirma que los países afines culturalmente se votan entre sí creando tres bloques diferenciados, a saber: el Bloque Occidental, el Bloque del Norte y el Bloque Mediterráneo.

La identidad europea es otra de las cuestiones investigadas en los estudios que hay sobre el certamen. Sin embargo, la característica principal de estos es investigarla a partir de un país concreto, demostrando así que una nación puede construirse a través del Festival. En ese sentido, a la hora de iniciar el presente trabajo es fundamental comenzar con los textos de Paul Jordan, conocido en el «mundo eurovisivo» como Dr. Eurovisión: «The Modern Fairy Tale: Nation Branding, National Identiy, and the Eurovison Song Contest in Estonia» (Jordan, 2014) y «The Eurovision Song Contest: Nation Branding and Nation Building in Estonia and Ukraine» (Jordan, 2011).

En ambos, se indica la importancia que ha tenido el evento en términos de creación de imagen y marca del país. Para Estonia, así como Ucrania y Finlandia, el Festival de Eurovisión ofreció la oportunidad de presentar una cierta narrativa de su identidad a un público más amplio. «Los países han utilizado el Festival de Eurovisión como una plataforma para expresar la europeización, y en ese sentido, ha sido una herramienta para construir una nación» (Jordan, 2011, p. 135).

Con este trabajo pretendemos dar una visión y enfoque diferente al Festival de Eurovisión, estudiándolo como un fenómeno que va más allá de lo musical, rigiéndose así bajo los objetivos culturales que persigue la Unión Europea de Radiodifusión.

\section{OBJETIVOS E Hipótesis}

Esta investigación comienza por dar respuesta a un interrogante que nace de la curiosidad personal. Este surge tras la indagación en el organismo que se encarga del programa: ¿el Festival de la Canción de Eurovisión cumple hoy en día los objetivos de la Unión Europea de Radiodifusión?

Por ello, una vez establecida la pregunta de investigación fundamental, puede decirse que nuestro principal objetivo es conocer si el Festival cumple con los objetivos de la UER señalados en sus estatutos que hacen referencia a la diversidad cultural e identidad de los pueblos. De manera implícita, la investigación plantea un objetivo secundario: presentar el Festival de Eurovisión como un fenómeno televisivo de carácter cultural.

Esta investigación parte de las siguientes hipótesis principales:

H1 El Festival de la Canción de Eurovisión garantiza la diversidad cultural para promover valores de tolerancia y solidaridad.

$\mathbf{H}_{2}$ El Festival de la Canción de Eurovisión protege y promueve la herencia cultural europea.

H3 El Festival de la Canción de Eurovisión refuerza la identidad de los pueblos, la cohesión social y la integración de todos los individuos, grupos y comunidades.

\section{Metodología}

En el planteamiento y desarrollo de una investigación, se hace necesario elegir una metodología que permita abordar en profundidad el objeto de estudio. El presente análisis se articula bajo la perspectiva cualitativa combinada.

Según Duverger (1962, en Berganza, 2005, p. 177), la investigación puede hacerse siguiendo dos métodos diferentes. Por un lado, la observación directa de la realidad social por medio de entrevistas, encuestas, cuestionarios y observación participante. Y, por otro lado, el estudio y el análisis de documentos diversos: documentos escritos (entre los que se encuentran libros, publicaciones diarias y periódicas, series estadísticas, etc.) y materiales audiovisuales. Por ello, se ha optado por una metodo- 
logía cualitativa combinada.

De acuerdo con Denzin (1970, en Vallés, 2005, p. 146) para los propósitos presentes la observación participante será definida como una estrategia de campo que combina simultáneamente el análisis de documentos, la entrevista a sujetos e informantes, la participación y la observación directa y la introspección. En este sentido, se recurre a lo vivido para enriquecer lo que se observa desde una postura de aproximación y distanciamiento.

Como expresan Ruiz Olabuénaga e Ispizua (1989, en Vallés, 2005, p. 143) la observación es una de las actividades comunes de la vida diaria. Esta observación común y generalizada puede transformarse en una poderosa herramienta de investigación social y en técnica científica de recogida de información.

Berganza (2005, p. 284) explica que la observación participante es el plan de recogida de datos en el que el investigador forma parte de la propia situación observada. Para familiarizarse con esta técni$\mathrm{ca}$, se parte de la circunstancia de haber sido antes participante ordinario del fenómeno objeto de estudio. En este sentido, se recurre a lo vivido para enriquecer lo que se observa desde una postura de aproximación y distanciamiento.

Recogiendo lo explicado anteriormente, se ha realizado una observación participante del Festival de la Canción de Eurovisión desde dos perspectivas. Por un lado, accediendo como espectadora y seguidora del certamen al Eurovision's Greatest Hits $^{1}$ y al videoencuentro con los posibles candidatos a representar a España en el Festival de 2016 que tuvo lugar en Madrid, en TVE. Por otra parte, se ha accedido a otros eventos con acreditación de prensa. Estos han sido: Eurovision: You Decide ${ }^{2}$, London Eurovision Party ${ }^{3}$ y el Festival de Eurovisión 20164. Para todo ello, se ha tenido en cuenta las siguientes caracterizaciones:

Tabla 1. Caracterización del rol técnico de observador participante, en relación al papel profano de participante ordinario

$$
\text { PARTICIPANTE ORDINARIO }
$$

Propósito único: realizar actividades correspondientes a la situación social en la que participa naturalmente.

Desatención selectiva, estado de bajar la guardia o de dar las cosas por supuesto.

Observación de ángulo cerrado, limitada al propósito inmediato de realización de las actividades corrientes.

Experiencia desde dentro de la situación desde la condición de miembro y parte de la escena.

Introspección natural. Uso corriente en la vida cotidiana de la experiencia personal para comprender la ajena.

No registro sistemático de actividades, observaciones, introspecciones.

\section{OBSERVADOR PARTICIPANTE}

Propósito doble: implicarse en actividades concernientes a la situación social a estudio y observar a fondo dicha situación.

Atención incrementada; estado de mayor alerta.

Observación de ángulo abierto, ampliada por el propósito añadido de estudiar los aspectos culturales tácitos de una situación social.

Experiencia desde dentro y desde fuera de escena, desde la doble condición de miembro y extraño.

Introspección aplicada. Explotación de la introspección natural como instrumento de investigación social.

Registro sistemático de actividades, observaciones, introspecciones.

Fuente: elaboración propia a partir de Vallés, 2005.

\footnotetext{
1 Concierto organizado por la BBC, celebrado en Londres en marzo de 2015 con motivo del 60 aniversario del Festival.

${ }^{2}$ Gala organizada por la BBC en la que se elegía al representante de Reino Unido en Eurovisión 2016. Tuvo lugar el 26 de febrero de 2016 en Londres.

${ }_{3}^{3}$ Fiesta pre-Eurovisión el 17 de abril de 2016 en Londres. A ella acudieron varios de los participantes en la 61 edición del Festival, entre ellos también se encontraba Barei, la abanderada española en Eurovisión 2016.

${ }^{4}$ El Festival de Eurovisión 2016 se celebró en Estocolmo (Suecia) durante los días 10, 12 y 14 de mayo.
} 


\section{LA UNIÓN EUROPEA DE RADIODIFUSIÓN}

La Unión Europea de Radiodifusión -European Broadcasting Union (EBU) en inglés- es la principal organización pública de medios de comunicación del mundo. En la actualidad cuenta con 56 países miembros (tanto de Europa como de fuera de ella). Su principal misión es hacer el servicio de los medios públicos indispensable. Tal y como señala el artículo II de sus Estatutos, la UER: «es una asociación profesional que tiene por objeto promover la cooperación entre sus miembros y con los organismos de radiodifusión del mundo entero, y representar los intereses de sus miembros en el campo de la programación, en el ámbito legal y técnico, entre otros».

Para ellos, los medios de comunicación de servicio público son la piedra angular de la sociedad democrática, por lo que tratan de ofrecerles unos servicios de primera categoría y un centro para el aprendizaje y el intercambio de conocimiento. Una de las actividades principales de la UER es la cooperación técnica, situándose a la vanguardia de la investigación y del desarrollo de los nuevos medios de comunicación contribuyendo al progreso de las nuevas técnicas de radio-televisión, tales como el sistema de datos de radio (RDS), la televisión digital (DVB) y la de alta definición (HDTV). La unión europea de radiodifusoras opera a través de dos redes:

- Euroradio: promueve el servicio público de la radio para garantizar que siga siendo protagonista clave en el mundo multimedia. Esto se logra a través de intercambio de música, de redes profesionales y la promoción activa de la radio digital e híbrida.

- Eurovisión: produce y distribuye en alta calidad eventos deportivos y noticias, así como programas de contenido cultural, de entretenimiento y de música. El primer intercambio de imágenes a través de esta red fue entre Reino Unido y Francia. Sin embargo, se cita la coronación de la reina Isabel II de Inglaterra en 1953 como el inicio de intercambios en esta red cuando diferentes canales de televisión europeos (Francia, Bélgica, Países Bajos, Alemania y Reino Unido) decidieron emitir en directo la misma señal del acontecimiento.

Tal y como aparece en el punto 1.2 del artículo I de sus Estatutos, los objetivos de la UER son contribuir en el campo de la radiodifusión a:

1. Promover y desarrollar el concepto de medios de comunicación de servicio público (radio, televisión y otros medios electrónicos) y sus valores. En concreto los adoptados en la Declaración de la UER sobre los valores fundamentales de los medios públicos: universalidad, independencia, excelencia, diversidad, responsabilidad e innovación.

2. Salvaguardar y mejorar la libertad de expresión y de información, las cuales son las bases esenciales de las sociedades democráticas y condiciones fundamentales para el progreso y desarrollo de cada individuo.

3. Potenciar la libertad y el pluralismo de los medios, de la información y de las ideas. Así como la formación libre de opiniones.

4. Emplear y desarrollar las últimas tecnologías de comunicación e información para que toda la población tenga acceso a esos medios.

5. Garantizar la diversidad cultural para promover valores de tolerancia y solidaridad.

6. Proteger y promocionar la herencia cultural europea y el desarrollo de sus creaciones audiovisuales, ofreciendo un abanico más amplio de programas y servicios.

7. Reforzar la identidad de los pueblos, la cohesión social y la integración de todos los individuos, grupos y comunidades.

8. Cumplir con el servicio público en información, educación, cultura y entretenimiento a través de la producción de una programación variada y de calidad.

\section{El FeSTival de LA CANCión de EuROVisión}

El Festival de Eurovisión es el festival internacional de música más grande y más visto, así como el más longevo de la televisión. En sus sesenta y un años de vida, ha catapultado a la fama a artistas de 
gran renombre como Céline Dion, Olivia Newton-John, Julio Iglesias y al grupo sueco ABBA. Pero han sido pocas las canciones que han cosechado un éxito mundial, entre ellas se encuentra Nel blu, dipinto di blu, más conocida como Volare, interpretada por el italiano Domenico Modugno en 1958.

El concurso de las canciones de las televisiones públicas es definido en algunos medios británicos como The Telegraph (2007) como «el evento cultural más terriblemente maravilloso del continente».

\subsection{Historia DEL FESTIVAL DE EUROVISIÓN}

A mediados de los años 50, los miembros de la Unión Europea de Radiodifusión decidieron reunirse y crear un comité que investigara la forma de unir a los países europeos en torno a un programa de entretenimiento. A finales de enero de 1955, este comité, encabezado por el Director General de la Televisión Suiza, Marcel Bezençon, tuvo la idea de crear un concurso de canciones, inspirándose así en el Festival de San Remo (en Italia). La idea fue aprobada por la Asamblea General de la UER en Roma el 19 de octubre de 1955 y se decidió que el primer «Grand Prix del Festival de la Canción» tuviera lugar en 1956 en Lugano (Suiza). En sus inicios fue ideado para unir Europa y levantar a las naciones desbastadas después de la Segunda Guerra Mundial para promover el entendimiento cultural, mientras que al mismo tiempo suscitaba nuevas técnicas de difusión. La idea original del concurso, y que continúa a día de hoy, es que las naciones (aquellas cuyas televisiones sean miembros activos de la UER) presentan canciones originales que posteriormente serán interpretadas y retransmitidas en directo.

El siguiente paso fue poner en común una serie de normas que fueran seguidas por los participantes, los cuales fueron en un principio siete: Bélgica, Francia, Italia, Luxemburgo, Países Bajos, Suiza y Alemania Occidental. Ese año, los jurados votaron en secreto y no hicieron públicas las clasificaciones, limitándose a proclamar la canción vencedora: Refrain, de la suiza Lys Assia. Con el tiempo, los organizadores del Festival se dieron cuenta de que el momento de las votaciones era uno de los mayores ganchos de la transmisión y decidieron hacerlas públicas. Dos años más tarde, en 1958, el «Eurovision Grand Prix» se convirtió en un evento anual.

España no participó en ninguno de los cinco primeros Festivales porque, como cuenta Pardo (2005), no tenía instalaciones técnicas capaces de unirnos con Europa. Fue en 1961 cuando debutó en el certamen de la mano de Conchita Bautista con la canción Estando contigo.

Del Festival de 1964 no se conserva ninguna copia íntegra, puesto que pocos días después de celebrarse se incendió el estudio donde se grabó. De lo que se tiene constancia es que fue Italia con Gigliola Cinquetti la que se llevó la victoria y que el trío TNT fue el que representó a España. Pardo relata:

La anécdota del Festival, transmitido en directo para toda Europa, fue la aparición de unos manifestantes, cargados de la inevitable pancarta, que cruzaron el escenario mientras cantaban los TNT con alusiones críticas a los regímenes políticos español y portugués. Esta circunstancia hizo que Televisión Española impusiera la norma de emitir con unos segundos de retraso los eventos internacionales que no podía controlar. (Pardo, 2005, p. 23).

La edición de 1968 en España estuvo rodeada de polémica. Joan Manuel Serrat fue en primer lugar el elegido para acudir ese año a Londres (sede del certamen), sin embargo, debido a que su intención fue la de cantar en catalán, TVE le retiró del certamen. A tan solo dos semanas antes del concurso, el ente público español decidió apostar por llevar a una joven llamada Massiel, que por aquellos días se encontraba de gira por México. La madrileña ganó por tan solo un punto, quedando en segundo lugar el Congratulations de sir Cliff Richard. Tras el triunfo de Massiel, España tuvo el encargo de organizar el Festival de Eurovisión en 1969. El lugar elegido fue el Teatro Real de Madrid y Salvador Dalí elaboró el cartel promocional. El gobierno de Franco levantó para la ocasión el estado de excep- 
ción para recibir a las delegaciones invitadas, aunque, a pesar de esto, Austria no acudió a la cita alegando que no quería enviar a ningún cantante a participar en un país que tenía un régimen dictatorial. Esa edición acabó con un cuádruple empate en la cabeza de la clasificación, y al no existir normas con respecto a este hecho, se proclamaron vencedoras: España, Reino Unido, Holanda y Francia.

Si hay un año que marca un antes y un después en la historia del Festival, ese es 1974:

\begin{abstract}
El gran éxito del año, quizás el mayor de toda la historia de Eurovisión fue la canción ganadora, $W$ aterloo de los suecos ABBA. Por primera vez se había incorporado la música pop al estilo comercial de las radios de la época a un Festival que pecaba de anticuado. Y había nacido un grupo que en los siguientes ocho años iba a triunfar constantemente con todos y cada uno de sus discos. Fue una auténtica revolución para el Festival cuya influencia duró mucho tiempo. (Pardo, 2005, p. 43).
\end{abstract}

El año 1998 estuvo marcado por el debate político y religioso que generó la representante israelí, la transexual Dana International. Los enfrentamientos ocurridos en Israel entre ortodoxos y laicos por la designación de Dana llenaron los informativos de toda Europa en las semanas previas del certamen, por lo que la representación israelí llegaba al certamen con mucha ventaja publicitaria sobre los otros participantes. La victoria de la cantante «reavivó en toda Europa el debate y el interés por el Festival» (Pardo, 2005, p. 91). Con la llega de la nueva era, desaparece la orquesta, permitiendo a los artistas utilizar una base musical pregrabada (backing track). En 2004 se introducen las semifinales debido al gran número de países que se dieron cita en Estambul. En 2008 participaron 43 países, por lo que la UER decidió hacer dos semifinales, situación que continúa hasta nuestros días.

El hecho histórico más relevante de la última década es la participación de Australia. La cadena australiana SBS fue invitada a participar, pasando directamente a la final, en el show televisivo en el año 2015 con motivo de la celebración del sesenta aniversario del mismo. Esta participación fue justificada por la UER como un regalo por haber retransmitido durante tantos años, desde 1983, el Festival. En la última edición del certamen, 2016, Australia se convertía en un país con pleno derecho a participar (a pesar de que la cadena no es miembro activo de la UER) aunque esta vez compitiendo como los demás: pasando por semifinales.

\title{
5.2. El FeSTival de EUROVISIÓN COMO EVENTO MEDiático
}

En sus sesenta y un años de vida, el Festival de Eurovisión se ha convertido en un fenómeno que traspasa el continente. En él concursan casi medio centenar de países, consiguiendo una audiencia de más de 200 millones de espectadores, consagrándose como el mayor evento no deportivo más visto en todo el mundo, y ha crecido de tal forma que ahora se lleva a cabo durante tres noches, las dos semifinales (martes y jueves) y la final (sábado). Dayan y Katz (1992) definen a este tipo de eventos como las grandes vacaciones de los medios de comunicación:

La diferencia más obvia entre los eventos mediáticos y el resto de géneros televisivos es que, por definición, no pertenecen a las rutinas de la programación. De hecho, son interrupciones de las rutinas; intervienen en el ritmo habitual de la televisión en nuestras vidas. [...] Se transmiten mientras están ocurriendo, en tiempo real, en directo y se organizan fuera de los medios. (Dayan y Katz, 1992, p. 5).

Bolin (2006) explica que el certamen comparte muchas características con otros eventos mediáticos internacionales como los Juegos Olímpicos y el Mundial de Fútbol. Pero, además, también lo asemeja a otros eventos anuales que son emitidos en todo el mundo, como pueden ser la gala de ceremonia de los Óscars o los premios de la cadena musical MTV. Él afirma que el Festival es muy similar a los eventos deportivos, entendiéndolo en el sentido de que es una competición entre nacio-

Ediciones Universidad de Salamanca / CC BY - NC ND $\quad$ Fonseca, Journal of Communication, n. 15, 2017, pp. 145-162 
nes, o al igual que en los Óscars, que es una competición entre actores. Este autor finalmente entiende que al tratarse de una lucha entre nacionalismos hace que el Festival de Eurovisión sea único en su género.

Por otra parte, Jackson (2007, en Jordan, 2011, p. 20) argumenta que el hecho de que el Festival tenga tantos seguidores hace que el Festival sea algo más que un evento mediático. En este sentido, podemos decir que el certamen, además de ser un evento mediático, es un evento especial:

Son eventos de carácter único y festivo, con su propia imagen, estatus, prestigio o marca, de una duración limitada y fija que llama la atención a inmensos medios de comunicación sobre las ciudades anfitrionas. Son eventos que por lo general implican una serie de actores y organizadores que planifican y controlan el evento, mientras que una audiencia está presente en el lugar donde experimentan el ambiente único del evento. (Skodra, 2010, p. 12).

Este tipo de eventos atraen la cobertura de los medios de comunicación a la ciudad anfitriona, así como a miles de periodistas, escritores de turismo, atletas o artistas mundialmente conocidos, aficionados y turistas que buscan ser parte de una experiencia única.

Dayan y Katz, en su libro Media events. The live broadcasting of history (1992), señalan que los eventos mediáticos son ceremonias que enganchan a un gran número de telespectadores, a una nación o a varias, y así mismo:

Están caracterizados por la norma de que hay que verlos, en la que la gente se dice una a otra que es obligatorio seguirlo. Hacen que los telespectadores celebren el evento reuniendo delante del televisor a grupos de personas, en vez de verlo solos [...] Estos eventos atraen a las mayores audiencias de la historia de la televisión. (Dayan y Katz, 1992, pp. 9-14).

Este seguimiento de la gente, con el paso de los años ha dado lugar a que ahora el Festival de Eurovisión se continúe a través de segundas pantallas. Este año Eurovisión ha dominado la conversación en redes sociales. En concreto, la edición de 2016 consiguió acaparar «la conversación social durante toda la noche, generando más de siete millones de comentarios» (RTVE, 2016). Así mismo, cuando se conoció que Ucrania era la ganadora «se estaban produciendo 72.915 tuits por minuto» (20 Minutos, 2016), convirtiéndose así esta red social en una de las mejores plataformas para que los espectadores puedan comentar el certamen. Twitter se ha convertido en una especie de «salón virtual», como explican Highfield et al. (2013, p. 318), en donde los miembros de la audiencia pueden reunirse para discutir y debatir, en tiempo real, lo que están viendo en la pantalla del televisor. En este sentido, como argumentan estos autores, esta red social se ha convertido en una extensión no oficial del Festival de Eurovisión, puesto que, a través de ella, el público puede participar en una comunicación directa, conversando y conectando con otros seguidores del certamen musical europeo.

Siendo conscientes de esto, Twitter desarrolló un hashtag (\#) especial para la semana del Festival de 2015; este estaba creado a partir del logo genérico del certamen, que tiene forma de corazón, junto con las banderas de los países participantes. Estos hashflags están habilitados en esta red social para ocasiones o eventos especiales, aunque en esta ocasión se utilizó por primera vez para una competición musical, puesto que anteriormente se habían utilizado para eventos deportivos, como el Mundial de Fútbol de 2014. En el Festival de Eurovisión de 2016, Twitter volvió a apostar por crear un hashtag especial para la celebración del concurso, pero esta vez solo utilizando el logo del certamen. 


\subsection{El FESTIVAL DE EUROVISIÓN COMO HERRAMIENTA CULTURAL: CONS- TRUCCIÓN DE IDENTIDADES}

Bjönberg (2007) argumenta que el Festival de Eurovisión es un evento en el que todos sus ingredientes de participación, véase la música, el idioma y la danza, son potenciales indicadores de la cultura nacional. El certamen es un escaparate de una experiencia cultural compartida. A este respecto, podemos ejemplificarlo con los ideales de la Unión Europea de «Unida en la diversidad», a pesar de que, como hemos explicado, el certamen no guarde relación directa con la Unión Europea. Este autor también afirma que las actuaciones en el programa de televisión llevan significados culturales asociados a los problemas de identidad nacional, regional y la identidad europea y sus representaciones musicales.

Eventos como el Festival de Eurovisión se convierten, como asegura Jordan (2005, p. 43), en vehículos para la promoción de la cultura a través de la participación y del alojamiento del evento en sí. La identidad europea, al igual que la identidad nacional, es una construcción cultural, un sentimiento de pertenencia a una comunidad imaginada. Las identidades europeas y las identidades nacionales no tienen que excluirse necesariamente: la pertenencia a un grupo no significa que no se pueda pertenecer a cualquier otro. En el Festival de Eurovisión, ambos espacios de identificación, tanto el nacional como el europeo, se llevan a cabo.

Bjönberg (2007, p. 16) cuenta que una de las muchas funciones de Eurovisión es «mostrar las representaciones musicales de cada identidad nacional». Bolin (2006, p. 191) afirma que el Festival de Eurovisión se ha convertido en una herramienta discursiva a la hora de definir el concepto de europeidad y las estrategias políticas de la europeización. Y de la misma forma, la página web de la UER señala que desde hace 60 años el Festival de Eurovisión ha sido el programa favorito de Europa, en el que, tras más de seis décadas, que han dejado más de 1400 canciones, se ha convertido en un moderno clásico, fuertemente arraigado de la cultura colectiva de Europa. De acuerdo con Bolin (2006) el Festival de Eurovisión es, además, una plataforma para la promoción de la nación. En ese sentido, este autor hace una comparación entre el evento y las Exposiciones Universales (World Fairs) del siglo XIX, en las que la organización del evento permite a los países venderse y mostrarse al público.

Los cambios que han tenido lugar en Europa se han reflejado en el Festival de manera más general. Muchos de los ganadores de la última década han procedido de estados nuevos entrantes (Estonia, Letonia, Ucrania, Serbia y Rusia) o de aquellos países que han participado desde los inicios y que se encuentran en la periferia de Europa, como Finlandia o Grecia (Fricker, 2009, pp. 1-2). Como explican Raykoff y Tobin, Eurovisión proporciona un contexto para examinar la definición de Europa y las nociones de identidad europea en el nuevo siglo (2007, p. 23). El concurso puede ser visto como una representación simbólica de Europa; como la configuración de Europa como un bloque unido. Para explicar cómo podemos ver la unidad del continente durante el certamen, basta con señalar varias de las frases que se han escuchado desde el inicio del concurso: «Good Evening, Europe! », «Europe, start voting now». Cuentan además Lehti y Smith (2003, pp. 183-184, en Jordan, 2005, pp. 40-41) que, desde la participación de Israel y Marruecos, se refuerza la noción de Europa como una construcción social. En este contexto, eventos como el Festival de Eurovisión pueden ser considerados como símbolo de la cultura popular europea, porque forma parte ya de un ritual tradicional de la televisión. El certamen representa un sentido de «unión» como parte de una rutina. Este aparente sentido de comunidad, por tanto, permite imaginar a los individuos una conexión real con otros miembros de diferentes Estados (Jordan, 2011, p. 11).

Catherine Baker escribe que el Festival ofrece dos oportunidades a los países para mostrar la nacionalidad de los mismos: en primer lugar, la actuación en directo, que va a estar relacionada con la promoción del cantante o de los cantantes; y en segundo lugar, la promoción de la ciudad y el país anfitrión. Baker continúa afirmando que estas posibles actuaciones de la nacionalidad, las cuales representan a más de 40 países, tanto de dentro como de fuera de Europa, crean una cierta presión para representar a la nación, basándose en conocidas y simplificadas imágenes positivas del país o región. 
El Festival de Eurovisión ha sido utilizado por las naciones participantes como una plataforma para la visualización de los aspectos de su patrimonio nacional, sea a través de la elección de los trajes o el estilo musical (Jordan, 2005, p. 46).

Los ejemplos que incorporan elementos musicales típicos del folclore de cada país, en su gran mayoría, podemos encontrarlos en los países del Este. Aunque a este respecto, encontramos algunas excepciones. Por ejemplo, Portugal siempre ha apostado por llevar su música y su folclore portugués. Por este motivo, el estilo musical que ha predominado en sus participaciones en el certamen ha sido el Fado. En el año 2011 cambiaron esta tendencia apostando por una propuesta que le mostraba a Europa que «la lucha es alegría» en clara referencia a la Revolución de los Claveles por la que pasó el país en 1974, siendo este, el clavel, el protagonista de la puesta en escena.

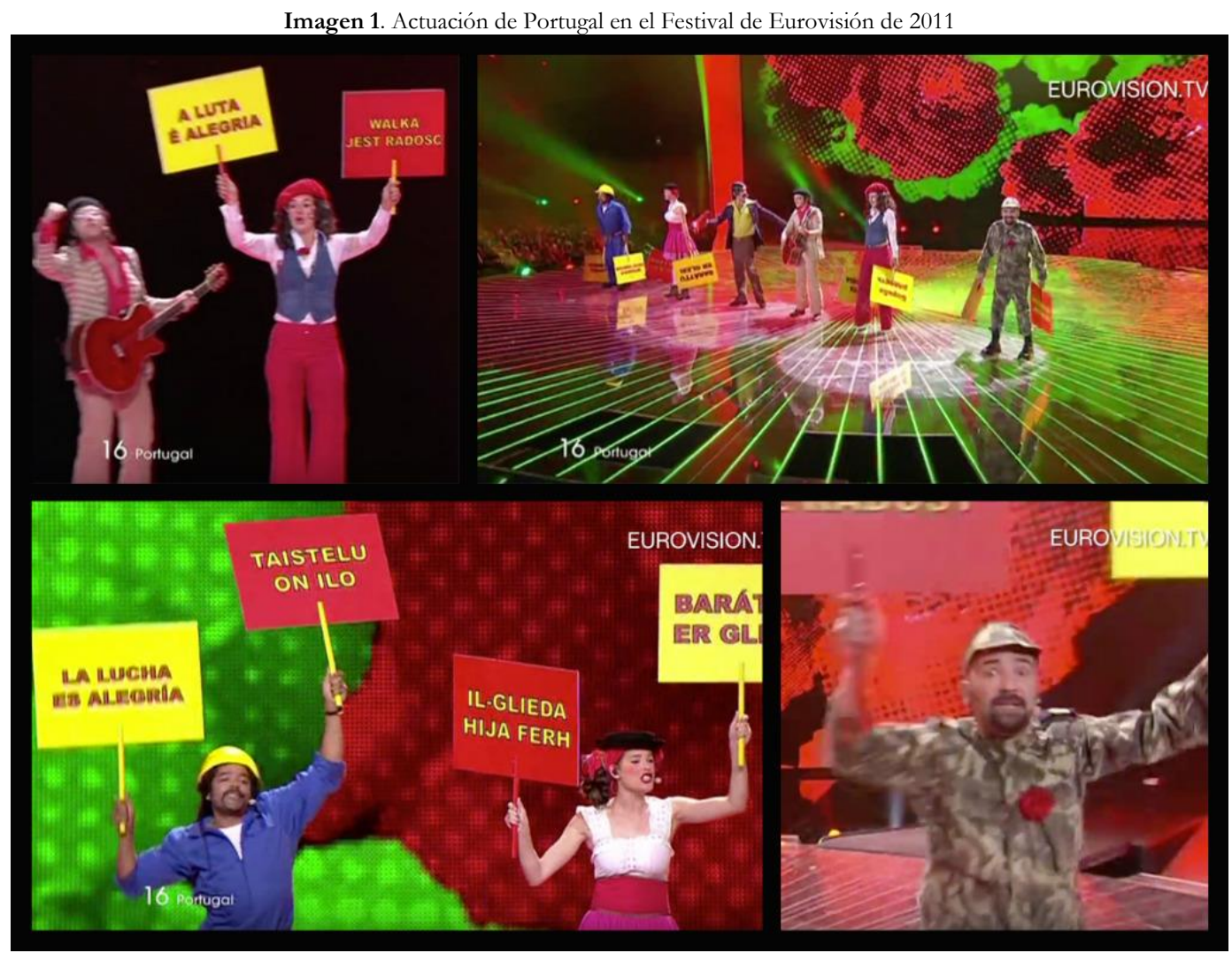

Fuente: Elaboración propia a partir de YouTube.

Baker (2008) escribe que los países del Este siguen la estrategia de centrarse en los estilos folclóricos que representan las viejas tradiciones o las tradiciones locales. Y, además, afirma que las regiones de la periferia de Europa maximizan sus posibilidades de éxito en el mercado de entretenimiento europeo mediante la presentación de algo exótico y distintivo.

Sin embargo, no solo podemos encontrar elementos que muestren la identidad de cada país en las canciones que compiten cada año. También lo encontramos en las actuaciones de los intermedios, o en el momento de las votaciones. Otra forma de apreciar la identidad nacional y europea lo podemos ver en los eslóganes que tiene el Festival y en las postales que presentan a cada país.

En sus inicios, el Festival de Eurovisión pretendía unir a los países a través de la música. Con el 
paso del tiempo, desde el propio programa se ha buscado crear ciertos elementos que ayudaran a transmitir ese mensaje de unidad, entre ellos se encuentran los eslóganes del certamen. Hay que remontarse al año 2002 para ver por primera vez uno en el Festival de Eurovisión. Los estonios decidieron darle a la 47 edición del certamen un tema con el fin de unificar la producción del evento en torno a una temática en común. En un principio, los eslóganes estaban enfocados a resaltar principalmente al lugar que ocupaba de cada país anfitrión en Europa. Sin embargo, ese mensaje de unidad que quiere transmitir el concurso se empieza a hacer patente a partir del año 2013.

Los ejemplos más fuertes de representación de una nación, afirma Jordan (2005), son los fragmentos de películas cortas que aparecen entre cada canción durante el Festival de Eurovisión. Estas tarjetas postales se parecen a las campañas de publicidad de turismo, pues son en esencia las representaciones del patrimonio de cada país (2005, p. 44).

Estas tarjetas postales se vieron por primera vez hace 40 años, en concreto en 1970, y tenían una duración de 30 segundos. En estas piezas, los abanderados de cada nación aparecían en los monumentos más representativos de cada país. A lo largo de gran parte de la historia del concurso, la secuencia de apertura de cada entrada ha sido retratada con una postal. Estas tienen varias funciones en el show. En primer lugar, sirven para dejar espacio entre actuaciones y así permitirles a los organizadores cambiar el escenario y prepararlo para las siguientes actuaciones. En segundo lugar, nos muestran las culturas, las tradiciones, y los paisajes de los países participantes, construyendo la identidad de cada país, presentándolos a través de pequeños fragmentos publicitarios, narrados por el comentarista de cada televisión y con el tiempo.

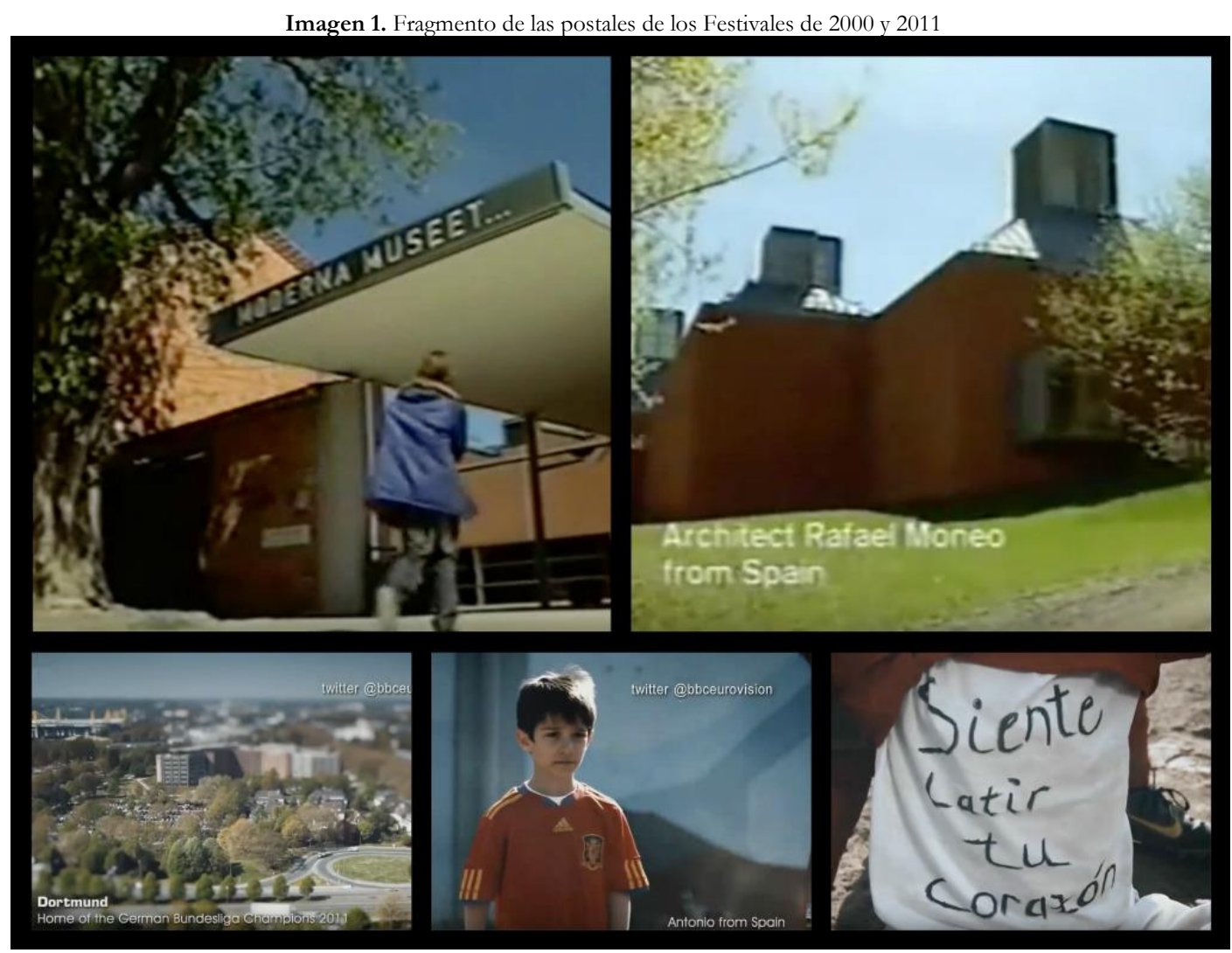

Fuente: Elaboración propia a partir de YouTube. 


\subsection{RASGOS POLÍTICOS EN EL FESTIVAL DE EUROVISIÓN}

Antes de que comience cada show, el regidor da una indicación básica: «iDisfruten, es música!». Sin embargo, hay una cuestión que desde la entrada del televoto juega un papel importante en la competición: la política. Esto es un tema común de debate que hace que, periódicamente, los medios investiguen acusaciones de irregularidades en la gestión del concurso, así como el problema de las tendencias y la influencia política sobre el sistema de votación del mismo. ¿Es Eurovisión política? ¿Influye la política en el certamen musical europeo?

Como decimos, con la llegada del televoto empezaron a dispararse las voces críticas que afirmaban que Eurovisión se había convertido en un campo de batalla político. Así mismo, también crecían las opiniones en torno a los votos fraudulentos en el concurso. A este respecto, la Unión Europea de Radiodifusión siempre ha intentado adaptar las normas y velar por el buen funcionamiento del concurso para que no se dé pie a comentarios de tal calibre.

Si nos remontamos tiempo atrás, es conocido que, en 2008, tras haber quedado en última posición el Reino Unido y al haberse proclamado Rusia como vencedora, Sir Terry Wogan anunció que iba a dejar de comentar el Festival para la BBC, afirmando que el certamen «había dejado de ser un concurso musical». Siguiendo esta línea de opinión, el año anterior, la victoria de Serbia en el Festival causó conmoción en Europa occidental, donde el público y los medios de comunicación criticaron la credibilidad de los resultados. De hecho, esta situación fue debatida en el Parlamento británico, donde el liberal demócrata Richard Younger-Ross denunció que el sistema de votación atentaba contra las relaciones entre los pueblos de Europa.

Ante esto, hay varios autores que han estudiado las votaciones del certamen a partir de fórmulas matemáticas y estadísticas. Yair es el primer autor en presentar un documento que aborda el tema del comportamiento de votos en el concurso. Tras analizar las votaciones entre 1975 y 1992 demostró la presencia de tres áreas principales que estaban basadas en sentimientos e intereses: el Bloque Occidental, el Mediterráneo y del Norte. Con todo, la evidencia científica existente parece sugerir que, efectivamente, tienden a aparecer determinados patrones de voto. Estudios posteriores extendieron su análisis hasta 2003, «añadiendo variables de parentesco lingüístico y, también culturales (la forma de afrontar la desigualdad social, el individualismo, la masculinidad, la tolerancia...)» (La Vanguardia, 2016).

Gatherer (2006), tras analizar las votaciones del Festival entre 1975 y 2002, identificó los siguientes bloques: el Benelux (Bélgica y Países Bajos), el Imperio Vikingo (Islandia, Noruega, Finlandia, Suecia, Dinamarca, Estonia, Letonia y Lituania), el Bloque Balcánico (Eslovenia, Croacia, Bosnia y Herzegovina, Turquía, Macedonia, Albania, Grecia, Serbia y Montenegro, Rumania y Chipre), el Pacto de Varsovia (Polonia, Ucrania y la Federación Rusa) y el Eje Pirenaico (Andorra y España).

Imagen 3. Bloques en el Festival de Eurovisión según Gatherer

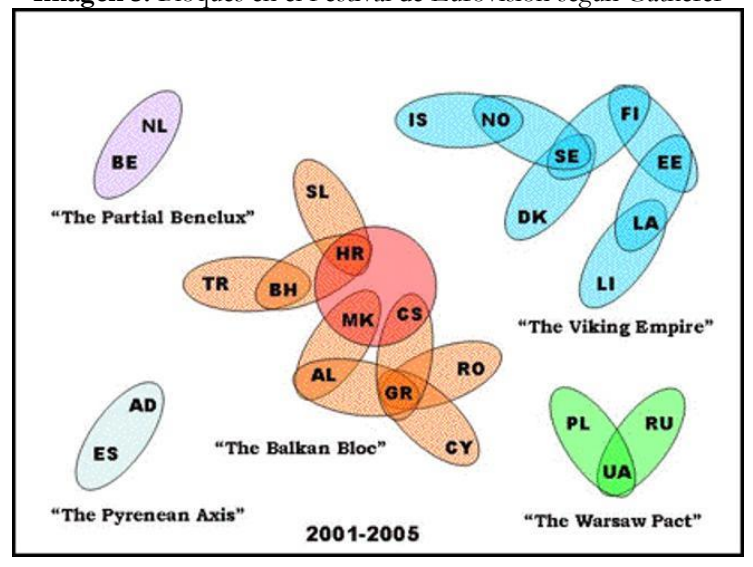

Fuente: Gatherer, 2006. 
Como vemos, a la hora de votar influyen los factores políticos y los culturales. No obstante, Blangiardo y Baio (2014) identificaron el impacto de la estructura social y geográfica en los patrones de voto, tras el análisis de dos décadas de Festival (entre 1998 y 2012). En su trabajo investigaron la presencia de tendencias positivas o negativas (lo que indica si existe el voto de castigo) en los votos en base a la proximidad geográfica, la migración y las características culturales de los países participantes. El análisis no encontró la evidencia de una tendencia negativa:

En conclusión, los resultados de nuestro modelo parecen sugerir que no hay ninguna tendencia negativa que emerja en el televoto. En algunos casos (y de acuerdo con los hallazgos previos en la literatura), encontramos tendencias positivas, las cuales se pueden explicar por las fuertes similitudes culturales, por ejemplo, debido a las similitudes en el lenguaje y la historia y en menos medida en la proximidad geográfica y migraciones. (Blangiardo y Baio, 2014, p. 2321).

Por lo que podemos concluir, en este repaso a los patrones de votación existente, que a la hora de votar prevalecen los rasgos culturales antes que los factores políticos. Sin embargo, a pesar de que la literatura nos muestre que no, que los factores políticos no influyen, sí es cierto que suelen estar presentes durante el certamen. Por ejemplo, en las letras de las canciones. En 2005, la entrada de Ucrania de ese mismo año, Razom nas bahato, interpretada por la banda de hip hop Greenjolly, había sido el himno de las protestas de la Revolución Naranja. Una vez seleccionada la canción, la UER se manifestó e insistió en que la letra contenía referencias políticas específicas que atacaban al presidente pro-ruso Viktor Yanukovich. Posteriormente, esos versos fueron retirados de la versión original de la canción. En el caso de España, en 2008, Baila el Chikichiki. O la de Georgia, en 2009, que llevaba por título We don't wanna put in («No queremos aguantar»). Desató la polémica porque a la hora de la pronunciación de esa frase se parecía a We don't wanna Putin («No queremos a Putin»). En el Festival de 2013, muchos acusaron a la canción suiza de lanzar un mensaje religioso (algo que también prohíben las reglas del Festival). El grupo Heilsarmee, que traducido al español significa Ejército de Salvación, llegaron al Festival con la canción You and $M e$ vestidos con el uniforme de dicho ejército. La UER les avisó de que deberían cambiar de nombre y de vestimenta, de lo contrario serían expulsados del concurso. Finalmente, lo hicieron y cambiaron el nombre del grupo por el de Takasa. Y en la última edición, la canción ucraniana titulada 1944, en la que la cantante, Jamala, canta una de las historias que le contó su bisabuela. En concreto, la tragedia que le ocurrió a su familia y a los tártaros de Crimea en 1944, mandando con ella un mensaje de memoria histórica para que la gente no olvidara el pasado. Si analizamos la letra, no hay evidencias de ningún mensaje político, solo se entiende que se refiere a ese hecho por la historia que la cantante cuenta en ruedas de prensa. La UER aseguró esto mismo, y le dejó participar.

\subsection{LA LENGUA COMO VEHÍCULO CULTURAL}

Ifversen (2002, en Jordan, 2011, p. 21) sugiere que el lenguaje, la religión, la tradición y las costumbres son algunos de los elementos que marcan la cultura. Y en este sentido, podemos decir que el idioma es un factor importante en la transmisión de un mensaje en las actuaciones de Eurovisión, así como una forma de mostrar la diversidad cultural sobre el escenario.

A lo largo de la historia del certamen, como hemos relatado previamente, ha habido un debate constante sobre en qué idioma tenía que interpretar cada artista su canción. Esto se refleja en las «políticas lingüísticas» de la UER, teniendo diferentes normas para regular el idioma a lo largo de las seis décadas de competición musical. Desde 1999, la UER impuso la norma de que los países tenían la oportunidad de cantar en el idioma que quisieran. Esto ha tenido un resultado interesante: el inglés se ha convertido en el idioma de elección para la mayoría de los participantes. Desde la nueva era, también se muestra esta tendencia a utilizar el inglés como lengua franca dentro del concurso. Ante esto, The Telegraph (2006) se muestra sarcástico y afirma que «Oscar Wilde debería haber definido Eurovisión como un continente entero dividido por un lenguaje común: el inglés». 
Gráfico 2. Idioma de las 64 canciones ganadoras del Festival de Eurovisión ${ }^{6}$

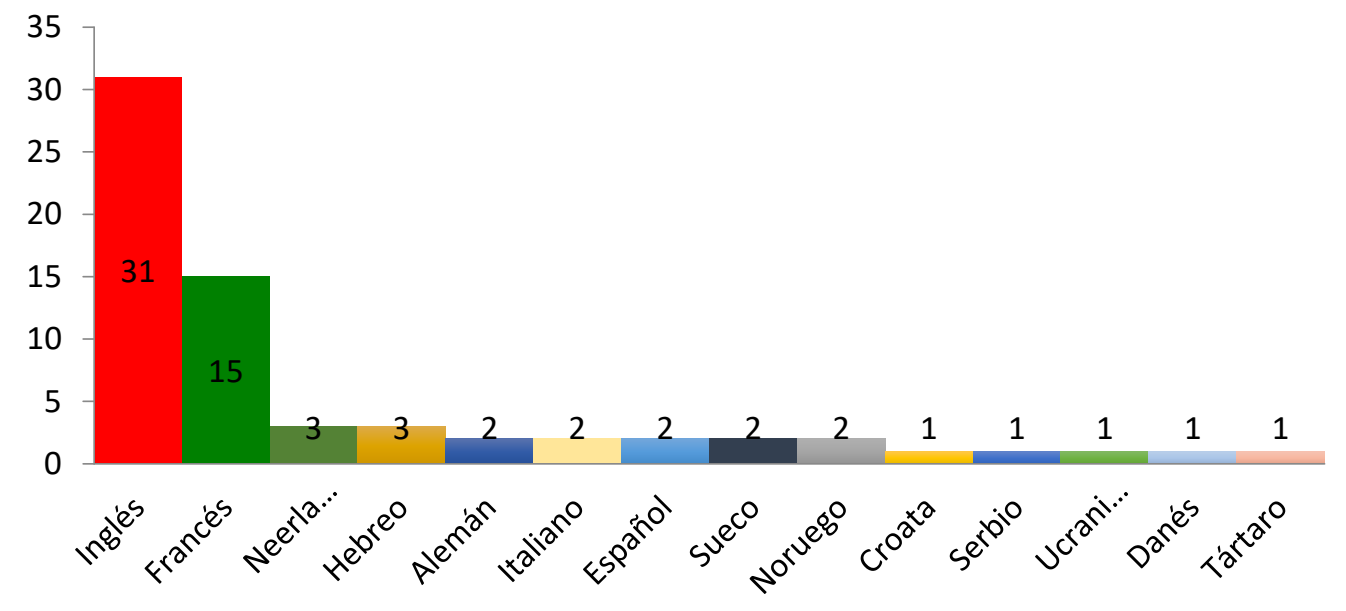

Fuente: elaboración propia.

¿Por qué el inglés domina en Eurovisión? Parece que hay dos razones principales para ello. En primer lugar, el inglés puede ser entendido por la mayoría de los europeos y, en segundo lugar, el negocio de la música pop, en general, está dominado por artistas que cantan en inglés.

No solo cantan en inglés los países del Este, sino que también lo hacen los países del centro de Europa. En el caso de España, tras sus 55 años de participación en el certamen, poco a poco se han ido introduciendo elementos en inglés. Empezó en el año 1988 con el grupo La Década y su canción La chica que yo quiero; como cuenta Pardo (2005), los responsables de TVE prefirieron titularla en inglés, Made in Spain, para abrirse así al mercado internacional. En 2002, fue la primera vez que se introducían fragmentos en inglés dentro de las canciones, en concreto, fue el Europe's living a celebration de Rosa López. Después vinieron los estribillos de las canciones íntegramente en inglés, como en el caso de 2014 con Ruth Lorenzo y su Dancing in the Rain. Pero no ha sido hasta el 2016, cuando España ha mandado una canción íntegramente en inglés: Say Yay! de Barei.

Aunque exista la tendencia de que ganan las canciones que están interpretadas en inglés, lo cierto es que hay tres, en estas últimas ediciones, que demuestran lo contrario. La primera, la ganadora de 2004 estaba interpretada en inglés y en ucraniano; la ganadora de 2007 estaba interpretada íntegramente en serbio; y, por último, la ganadora de 2016, que canta su canción en inglés y en tártaro de Crimea (un idioma minoritario). Sin embargo, la diversidad cultural, en cuanto a idioma, no solo la vemos en las canciones ganadoras. Durante más de seis décadas hemos podido escuchar estos idiomas sobre el escenario: sueco, checo, catalán, español, romance, luxemburgués, noruego, vienés, montenegrino, griego antiguo, noruego, udmurto, rumano, ruso, la lengua romaní, ucraniano, eslovaco, criollo antillano, võro, napolitano, portugués, islandés, maltés, hebreo, albanés, crimeo, esloveno, armenio, árabe, lituano, macedonio, estonio, bretón, griego póntico, croata, búlgaro, georgiano, bosnio, letón, serbio, alemán, húngaro, corso, polaco, irlandés, finés, holandés, samogitiano, turco, danés, francés, tahitiano, suajili y azerí. Además de canciones en lenguaje de signos y en idiomas inventados.

\footnotetext{
${ }^{6}$ Aclaración: a pesar de que haya habido 61 ediciones del Festival, lo que haría un total de 61 ganadores, también se contabiliza el empate a cuatro países de 1969, por lo que hace un cómputo de 64 ganadores.
}

Ediciones Universidad de Salamanca / CC BY - NC ND $\quad$ Fonseca, Journal of Communication, n. 15, 2017, pp. 145-162 


\title{
5.6. REPRESENTACIÓN DE LOS VALORES SOCIALES
}

Una vez que Conchita Wurst se proclamó ganadora del certamen en 2014, el presidente del gobierno austriaco, Heinz Fischer, tachó el hecho como algo que no era solo una victoria para Austria, sino que era una victoria para la diversidad y la tolerancia en Europa.

Sin embargo, la tolerancia no es un tópico nuevo de moda en el certamen. Además de en Conchita, tenemos que poner el foco de atención a la victoria de la transexual Dana International en 1998. Esto sirvió como una reivindicación del Festival como un certamen abierto y tolerante, sin embargo, este hecho es algo que el concurso trae consigo desde su primera edición en 1956, como cuenta Wolther (2014):

\begin{abstract}
Tolerancia para los artistas que cantan las alabanzas a sus países, aunque no estén de acuerdo con ellos. Tolerancia para los idiomas que pueden ser poco agradables para nuestros oídos. Y tolerancia para las diferentes preferencias culturales de música y puestas en escena. El Festival de Eurovisión no es un espectáculo para personas intolerantes, de mente estrecha o xenófoba, simplemente debido a la diversidad con la que cuenta este programa. (2014, pp. 49-51).
\end{abstract}

Una vez que son elegidas las canciones, las palabras como tolerancia, libertad, inclusión, respeto y modernidad, se convierten en protagonistas de los discursos de las delegaciones y de los artistas. Porque, en definitiva, todos tratan de transmitir un mensaje cuando están sobre el escenario de Eurovisión: Hungría en 2014 cantó en contra de los malos tratos, Suecia en 2015 lanzó un mensaje contra el bullying y Países Bajos este año ha protestado en contra de las demandas de la sociedad, pidiéndole a la gente que se tome la vida con calma.

\subsection{REPRESENTACIÓN DE MINORÍAS}

La representación idiomática en el Festival de Eurovisión ha traído consigo la representación de las minorías, por el hecho de que sobre el escenario de Eurovisión se han cantado canciones en idiomas minoritarios y casi olvidados. No obstante, también podemos ver el reflejo de otras minorías dentro del certamen. Así pues, según las Naciones Unidas en su documento Derechos de las minorías: Normas internacionales y orientaciones para su aplicación, se explica que no hay ninguna definición internacionalmente acordada sobre qué grupos constituyen minorías. Sin embargo, Capotorti define minoría como:

\begin{abstract}
Un grupo numéricamente inferior al resto de la población de un Estado, que se encuentra en una posición no dominante y cuyos miembros, que son nacionales del Estado, poseen características étnicas, religiosas o lingüísticas diferentes de las del resto de la población y manifiestan, aunque solo sea implícitamente, un sentimiento de solidaridad para preservar su cultura, sus tradiciones, su religión o su idioma. (Capotorti, 1979, p. 1).
\end{abstract}

Siguiendo esta definición, la primera representación de una minoría tuvo lugar en 1964. Anneke Grönloh, natural de Indonesia, pero de ascendencia neerlandesa, representó a este país en esa edición. Países Bajos sería el primero que llevaría como representante a la primera persona de color que pisara el escenario de Eurovisión.

Hay muchos ejemplos de esto a lo largo de la historia del certamen. En el caso de España, se ha llevado representantes que pertenecían a una minoría: la etnia gitana. Primero con Peret, en 1974, en 1983, con Remedios Amaya, en 1990, con el dúo Azúcar Moreno, y por último, en 1996, con Antonio Carbonell.

Las personas con discapacidad también han tenido su hueco dentro del Festival de Eurovisión. Fue España quien inició esto en 1992, eligiendo a Serafín Zubiri (que repitió también en 2000), un 
cantante, pianista y compositor invidente. Siguiendo sus pasos, se encuentra Corinna May, que representó a Alemania en el 2002 y Diana Gurskaya, que representó en 2008 a Georgia. En 2015, Monika Kuszyn $\square$ sk, representando a Polonia, ha sido la primera persona en silla de ruedas que ha pasado por el Festival. En esa edición también participó el grupo finlandés Pertti Kurikan Nimipäivät, el cual estaba integrado por cuatro músicos con autismo y síndrome de Down.

De la misma forma, en Eurovisión también se ha dado cabida a las minorías a través de los diferentes estilos musicales. En 1980, Noruega representó al pueblo lapón con su propuesta. En 2004, el võro fue el protagonista de la canción de Estonia, mostrando así esa lengua y esa música al mundo. En este repaso, también hay que mencionar al grupo finlandés de heavy metal que conquistó a Europa en el año 2006: Lordi. En su actuación, el grupo apeló a la identidad cultural nacional al usar los tradicionales sombreros de cuatro alas (llamados Sami), mientras portaban la bandera de Finlandia, lo que era un medio visual para encarnar un sentido de comunidad nacional, la banda construyó una identidad pública que indica una representación simbólica del público finlandés. Por otra parte, el líder de la banda, Mr. Lordi, ha declarado en muchas entrevistas públicas que pertenece a una minoría y a una subcultura y que su victoria fue un triunfo para la tolerancia (Pajala, 2006, p. 366, en Rinne y Häyhtiö, 2007, pp. 340-341).

\section{CONCLUSIONES}

Los orígenes del Festival de Eurovisión se encuentran en 1956, año en el que Europa estaba aún recuperándose de la Segunda Guerra Mundial. Por aquel entonces, el hecho de unir a los países a través de la música, como cuenta Pardo (2005, p. 14) fue tan innovador y tan importante «como la decisión de crear el euro como moneda común cuarenta y cinco años más tarde». Hubo un tiempo en el que las baladas en francés, los vestidos largos y pomposos eran los protagonistas de un Festival que había nacido con la intención de retransmitirse cada año por radio. Ahora, sesenta décadas más tarde, el certamen se ha convertido en uno de los fenómenos televisivos más importantes del año. En todo este tiempo, el concurso en el que participaron inicialmente siete países ha evolucionado hasta el punto de que actualmente es un espectáculo de tres noches en el que cuarenta y tres naciones compiten por llevarse un premio que acredita que tienen la mejor canción europea.

Sin embargo, en medio de todo el espectáculo, es fácil olvidar que el Festival de Eurovisión es una de las pocas tradiciones paneuropeas que conservamos. Independientemente de los retos a los que se tiene que enfrentar Europa, el certamen musical europeo sigue cumpliendo con su objetivo principal a día de hoy. No importa de dónde venimos, en lo que creamos, el tipo de música que nos guste o qué tradiciones celebremos, es un día en el que podemos unirnos gracias a la música.

Como hemos visto en los estudios que existen sobre los patrones y las tendencias en las votaciones del certamen, la política tiene poca trascendencia, siendo los rasgos culturales, idiomas e historia compartida entre los países lo que más influye a la hora de votar.

La diversidad cultural, además de en los idiomas, la vemos en los estilos musicales. Si bien es cierto que ahora hay una tendencia de elegir estilos anglosajones a la hora de presentarse al certamen, siguen apareciendo países que apuestan por seguir mostrando sus tradiciones y culturas sobre el escenario. Estos países, que en su gran mayoría son del Este, siempre llevan propuestas más locales o más nacionales, porque, para ellos, Eurovisión es la única oportunidad que tienen para abrirse y mostrarse al mundo, es el momento del año en el que pueden mostrar su cultura a los más de 200 millones de espectadores que van a ver el concurso.

El evento es, en efecto, un ritual cultural que se repite cada año y que va más allá de lo musical, haciendo que la identidad nacional esté presente durante toda la gala. Todas las ediciones son distintas y nunca se pueden comparar, pero lo que tienen en común es que, haciendo uso de diferentes recursos, como pueden ser las postales o las actuaciones de los intermedios e incluso el momento de conexión con los portavoces de cada país para dar las puntuaciones, se muestra la identidad de los países participantes. Este evento cultural, además, es una oportunidad para que los países participantes (in- 
cluyendo a los no europeos, como Israel, Azerbaiyán o Australia) se sientan parte de un todo, de una comunidad y de un continente desde el minuto uno en el que los presentadores le dan las buenas noches a Europa.

En esa diversidad y unidad de los países, se incluye también los valores que transmite el Festival. Valores como la tolerancia, el respeto, la amistad (entre los representantes); así como los mensajes que se lanzan en el escenario del Festival, es algo que, incluso en nuestros días, sigue siendo importante. El Festival de Eurovisión ha ido perdiendo su esencia en algunos países. Los del centro de Europa no tienen que depender de los estereotipos exóticos, como los del Este, para crear una fuerte marca del país, porque ya la tienen. Estos se presentan con una identidad plural sobre el escenario, puesto que su actuación en el certamen es solo una pequeña parte de su representación nacional. Ciertamente, el evento proporciona una plataforma para los estados periféricos para competir con los países occidentales, no en términos políticos, sino en términos culturales. El Festival se presenta como una oportunidad de ver a los países como potencias culturales. Por ese motivo, es importante aclarar qué es el certamen y devolverle a la sociedad el significado que tiene el Festival de Eurovisión, por lo que por ello aportamos nuestra propia descripción significativa del concurso, definiéndolo como un evento mediático anual que forma parte de la herencia cultural europea en el que los países participantes muestran su propia identidad garantizando así la diversidad cultural, promoviendo con esto la integración de todos los individuos, grupos y comunidades y cumpliendo así con los objetivos de la Unión Europea de Radiodifusión.

\section{BIBLIOGRAFÍA}

Ayllón, J. L. (2004). Eurovisión, un fenómeno paranormal. Madrid: Editorial ALFASUR.

Baker, C. (2008). Wild Dances and Dying Wolves: Simulation, Essentialization, and National Identity at the Eurovision Song Contest. Popular Communication, 6(3), 173-189. doi: http://dx.doi.org/10.1080/15405700802198113

Barei, reina de las redes en un espectáculo de millones de tuits. (15 de mayo de 2016). RTVE. Recuperado de http://www.rtve.es/television/20160515/barei-reina-redes-espectaculo-millonestuits/1351088.shtml

Berganza, M. y Ruiz, J. (2005). Investigar en Comunicación. Guia práctica de métodos y técnicas de investigación social en Comunicación. Madrid: Mc Graw Hill.

Björnberg, A. (2007). Return to ethnicity: The cultural significance of musical change in the Eurovision Song Contest. En I. Raykoff, I. y T. Robin (eds.), A song for Europe: popular music and politics in the Eurovision Song Contest (pp. 13-25). Aldershot: Ashgate.

Blangiardo, M. y Baio, G. (2014). Evidence of bias in the Eurovision song contest: modelling the votes using Bayesian hierarchical models. Journal of Applied Statistics, 41(10), 2312-2322. doi:10.1080/02664763.2014.909792. doi: http://dx.doi.org/10.1080/02664763.2014.909792

Bolin, G. (2006). Visions of Europe: Cultural technologies of nation-states. International Journal of Cultural Studies, 9, 189-206. Recuperado de https://www.academia.edu/962812/Visions of Europe. Cultural Technologies of Nation$\underline{\text { states }}$

Capotorti, F. (1979). Study on the rights of persons belonging to ethnic, religious and linguistic minorities. Naciones Unidas.

Cebrián, M. (2003). Estrategia multimedia de la televisión en Operación Triunfo. Madrid: Editorial S.L. Ciencia 3. Distribución.

Dayan, D. y Katz, E. (1992). Media events. The live broadcasting of history. Cambridge: Harvard University Press. Recuperado de http://bit.ly/25QEfEC

Derechos de las minorías: Normas internacionales y orientaciones para su aplicación (s. f.) Recuperado de http://www.ohchr.org/Documents/Publications/MinorityRights sp.pdf 
Eurovision Song Contest. EBU. Recuperado de http://www3.ebu.ch/projects/tv/eurovision-songcontest.html

Fraguas, T. (14 de mayo de 2016). La guía definitiva para entender la geopolítica en Eurovisión. La Vanguardia. Recuperado de http://www.lavanguardia.com/television/tv-or-nottv/20160514/401790684306/geopolitica-bloques-paises-eurovision-espana.html

Gatherer. D. (2006). Comparison of Eurovision Song Contest Simulation with Actual Results Reveals Shifting Patterns of Collusive Voting Alliances. Journal of Artificial Societies \& Social Simulation, 9(2). Recuperado de https://www.researchgate.net/publication/5140466 Comparison of Eurovision Song Contest Simulation with Actual Results Reveals Shifting Patterns of Collusive Voting Alliances

Highfield, T. et al. (2013). Twitter as a technology for audiencing and fandom: the \#eurovision phenomenon. Information, Communication \& Society, 16(3), 315-339.

Jordan, P. (2009). Eurovision in Moscow: Re-Imagining Russia on the Global Stage. E-Sharp, 14, 39-61.

Jordan, P. (2011). The Eurovision Song Contest: Nation Branding and Nation Building in Estonia and Ukraine. Tesis doctoral, Universidad de Glasgow. Recuperado de http://theses.gla.ac.uk/2972/

Jordan, P. (2014). The Modern Fairy Tale: Nation Branding, National Identity and the Eurovision Song Contest in Estonia. Tartu: University of Tartu Press.

Katz, E. (1980). Media Events: The Sense of Occasion. Studies in Visual Communication, 6, 84-89. Recuperado de http://repository.upenn.edu/asc papers/263.

L., M. (19 de mayo de 2013). La audiencia española mantiene su interés por Eurovisión a pesar de los malos augurios. Eurovision-Spain. Recuperado de http://www.eurovisionspain.com/iphp/noticia.php?numero $=8815$

Maurey, Y. (2009). Dana International and the politics of nostalgia. Popular Music, 28(1), 85-103. doi: https://doi.org/10.1017/S0261143008001608. https://www.jstor.org/stable/pdf/40212428.pdf?seq=1\#page scan tab contents

Mandinaveitia, E. (15 de mayo de 2016). Eurovisión arrasa en Twitter. 20 Minutos. Recuperado de http://blogs.20minutos.es/masquemedios/2016/05/15/eurovision-arrasa-en-twitter/

Pardo, J. M. (2005). Medio siglo del Festival de Eurovisión. Madrid: RAMA LAMA.

Raykoff, I. y Robin, T. (2007). A song for Europe: popular music and politics in the Eurovision Song Contest. Aldershot: Ashgate.

Rinne, J. y Häyhtiö, T. (2007). Hard Rock Hallelujah! Empowering Reflexive Political Action on the Internet. Jounal for Cultural Research, 11(4), 337-358. doi: http://dx.doi.org/10.1080/14797580802038702

Skodra, C. (2010). Destination Branding and Spotlight Cultural Events. Media narratives of Eurovision and Finland. Tesis de maestría, Sibelius-Akatemia. Recuperado de: http://ethesis.siba.fi/files/nbnfife201007082161.pdf

Statutes of the European Broadcasting Union. 3 de diciembre de 2015. Recuperado de http://www.ebu.ch/files/live/sites/ebu/files/About/Governance/Statutes EN.pdf

Vallés, M. A. (1997). Técnicas cualitativas de investigación social. Reflexión metodológica y práctica profesional. Madrid: Síntesis Sociología.

White, J. (19 de marzo de 2007). Eurovision is tuneless, but inspirational. The Telegraph. Recuperado de http://www.telegraph.co.uk/comment/personal-view/3638564/Eurovision-is-tuneless-butinspirational.html

Wolther, I. (2015). You wouldn't know me at all. Texte: Public Service Media in Europe, 14, 46-51.

Yair, G. (1995). «Unite Unite Europe»: The Political and Cultural Structures of Europe as Reflected in European Song Contest. Social Networks, 17, 147-161. Recuperado de https://www.academia.edu/4190892/Unite Unite Europe The political and cultural structur es of Europe as reflected in the Eurovision Song Contest 